\title{
The Influence of Gender Factor on Development of Stereotypical Image of a Specialist (Lawyer) of Future Profession in Students
}

\author{
Mykola Holovko ${ }^{1}$, Svitlana Holovko ${ }^{2}$, Yrii Zhuk, ${ }^{1, *}$ \\ ${ }^{1}$ Institute of Pedagogy of the National Academy of Pedagogical Sciences of Ukraine, Ukraine \\ ${ }^{2}$ Faculty of Law, National Aviation University, Ukraine
}

Received January 30, 2020; Revised March 26, 2020; Accepted April 24, 2020

Copyright $\mathrm{C} 2020$ by authors, all rights reserved. Authors agree that this article remains permanently open access under the terms of the Creative Commons Attribution License 4.0 International License

\begin{abstract}
The purpose of this paper is to find out the peculiarities of the influence of gender factor on the motivation of choosing the future legal profession and development of stereotypical image of a specialist of this profession in students. The research is based on an experimental method, measuring instruments and procedures of which (specially designed questionnaires) were focused on establishing the influence of gender factors on the development of future profession image in university students (on the example of future lawyers). Determining and describing the characteristics, selected for the experiment, made it possible to put them uniquely in ordinal scale, to highlight the linear arrangement of objects on some real line, and to make ranking. Factor analysis and variance analysis were used to process and interpret the measurement results. Results: taking into account gender aspects, it is suggested the following specific measures for improvement of the educational process of higher education institutions, namely: creation of equal opportunities for personal expression, expression of activity and initiative of students of both sexes; use of active communication of processes on the basis of "gender alignment" (organization of discussions and joint discussions of educational problems and professional practical situations, role-playing games with involvement of students of both sexes, use of collective methods and forms of organization of educational and cognitive activity of students in mixed groups); development of skills of gender reflection and partnership between students of different sexes; development of the ability of teachers to ensure gender equality in relation to the students audience.
\end{abstract}

Keywords Stereotype Image of Future Profession, Gender Approach, Factor and Variance Analysis, Legal Profession

\section{Introduction}

Every profession has its own set of stereotypes as its personified images. Person-centered peculiarity of the mechanisms of development of professional stereotypes as images-types significantly influences the formation of professional consciousness of future specialists.

In this context, investigations of interpretation peculiarities and comprehension of professional image and motivational sphere of personality of university students acquire a particular significance as components of professional orientation (interests, attitudes, values-based orientations, etc.) taking into account a gender approach.

\section{Analysis of Basic Research and Publications}

Modern psychological and pedagogical studies emphasize that images in the mind of the individual are formed under the influence of the subjective tendencies, interests and ideals of the individual and are colored in intimate and personal shades, inseparable from the personal life experience of the subject. By the term "image" in this research, we mean such an idea of a real object, which only approximately corresponds to the original by virtue of subjective perception of reality by the person.

The mechanism of development of stereotypes of the future profession is based on a system of moral and evaluative ideas concerning the subjects of professional activity and is an important factor at the stage of choosing a profession [1-3]. On the other hand, psychological studies prove that socio-professional stereotypes, acting as moral and ethical norms, laws and rules of behavior, attitudinal 
and situational factors determine a level of productivity in the process of situation assessment and decision-making [4], [5].

It is known that the term "stereotype" was introduced in 1922 by sociologist William Lippmann [6], who interpreted it as "a pictures in our heads". Currently, the stereotype is considered as a social attitude with a lack of cognitive component (lack of knowledge, misinformation, outdated data). As an attitude, a stereotype largely determines human behavior, and the process of stereotyping is an objective phenomenon of the formation of consciousness of the individual, structuring and displaying elements of the surrounding world. According to Tatyana Yevgenievna Vasil'eva stereotypes have rather complex and independent mechanisms of self-regulation, the degree of stability of a stereotype depends both on external circumstances and on their specific carriers (society, group, personality) with their usual ideas, empirical moods, which overcome the system of explications, sometimes are united in a holistic scientific or political picture of the world [7]. In the paper [8], the author notes that in its content a stereotype is only an image-conception with indistinct boundaries, and only verbally expressed assessment forms a clear opinion concerning the qualities of people of certain segment. Examining the role of stereotypes in the process of formation of ideas and evaluative judgments of an individual, Ihor Semenovych Con [9] asserts that stereotype is a preconceived notion concerning the humans' and phenomena's abilities, which is not based on direct valuation of each phenomenon, but is derived from standardized judgments and expectations.

Under the current conditions, the research of a professional orientation of university students through studying personal ideas concerning the image-type of the chosen profession, taking into account a gender approach, is of particular relevance. At the same time, stereotypes, as a form of individual consciousness of high school graduates, fulfill a social and regulatory function, acting as an important component of the system of factors that influence the formation of goals concerning the direction of further professional training, as well as motivation for admission to an appropriate higher education institution, which is reflected in certification evaluations according to the results of an external independent evaluation. This complicates an identification of specific pedagogical measures for the formation and development of professional direction during the period of studying, in particular in legal education, which actualises this problem, especially within the conditions of current reforms in the field of education and various spheres of jurisprudence.

The purpose of the article is to find out the peculiarities of the influence of gender factor on motivation of choosing a future legal profession and development of stereotypical image of a specialist of this profession in students.

\section{Materials and Methods}

The research is based on an experimental method, measurement tools and procedures of which (specially designed questionnaires) were focused on establishing the influence of gender factors on the formation of future profession image in university students (on the example of future lawyers). Determining and describing the characteristics, selected for the experiment, made it possible to put them uniquely in ordinal scale, to highlight the linear arrangement of objects on some real line, and to make ranking. Factor analysis and variance analysis were used to process and interpret the measurement results. Faculty of Law of National Aviation University became an experimental basis for conducting the sociological research, and the respondents were the first year students majoring in "Law".

\section{Results and Discussion}

The hypothesis of the research lies in the fact that the system of characteristics of the specialist, which is formed in the first year university students, depends on the gender of the student and is related to the certification evaluation of the external independent evaluation in the subject, required for admission to this specialty.

The main measurement tool was the questionnaire designed by the authors, which consisted of 29 self-assessment criteria concerning the professional profile of a lawyer (Appendix 1). These characteristics were selected by the authors of the methods in the process of analysis of literature, devoted to research in the field of legal psychology [10-12], as well as taking into account the general competencies of the graduate of the Bachelor degree and his training outcome, defined by the Standard of higher legal education in Specialty "081 Law" sphere of Knowledge "08 Law". In particular, the following competencies were taken into account: ability to think in abstract, analyze and synthesize; ability to apply knowledge in practical situations; ability to study and master modern knowledge, ability to be critical and self-critical; ability to work in a team, ability to act on the basis of ethical considerations (motives); ability to exercise his rights and responsibilities as a member of society, to realize values of civil (free democratic) society and the need for its sustainable development, the rule of law, the rights and freedoms of a human and a citizen in Ukraine; ability to be aware of equal opportunities and gender issues; ability to determine the vigour of arguments in the process of evaluating previously unknown conditions and circumstances; ability to analyze social processes in the context of the analysed problem and demonstrate his own vision of how to solve it; ability to formulate his own well-founded judgments based on the analysis of known problem, evaluate drawbacks and advantages of arguments, analyze known problem, independently identify the 
circumstances, in which help is needed, and act according to the received recommendations; ability to work in a group, form own contribution to the performing tasks of the group [13].

When working with the questionnaires, respondents were asked to rate the importance of the lawyer's characteristics (personal qualities), rating on a scale from 1 to 10 (10 maximum degree of importance). It took 15 minutes to complete the task.

The experiment in this research was built on the basis that allowed us to establish the influence of gender factors on the development of the image of a lawyer. During the survey, a respondent did not receive any external evaluation regarding the correctness of the evaluation process of the suggested characteristics in the questionnaire. In addition, the description of the characteristics, selected for the experiment helped to put them uniquely in ordinal scale. This, in turn, was allowed to introduce the linear arrangement of objects on certain real line, that is to make ranking directly in the process of evaluation.

Although the numerical values of the ordinal scale cannot be added, subtracted, divided or multiplied, but the interpretation of data, was obtained with the help the ordinal scale, a wide range of statistical means (for example correlation, variance and factor analysis). This explains widespread use of the ordinal scale of measurements in psychological and pedagogical studies [14].

The essence of "ranking" implies a direct order of objects by the respondent according to internal criteria accepted by him. The ranking procedure consists of a fixed set of objects in descending order of the attribute given. Usually, such a procedure is completely subjective [15]. The hierarchy established by a respondent is recorded in the tables of object numbers, which then are converted into the evaluation matrices, that is, matrices contain the position of each object according to each trait that is evaluated.

The following set of personal characteristics of the lawyer's image was used to construct the evaluation matrices: analytical thinking, communicativeness, critical appraisal of facts, logic of judgments, unbiased judgments, ability to set priorities, leadership qualities, self-assessment, self-control, objectivity of judgments, independence of judgments, ability to adapt in a team, adherence to principles in approaches, ability to select essential, tolerance, democracy in communication, ability to model circumstances, accuracy in work, timeliness of tasks performance, diligence, ability to manage time, determinativeness, confidence, ability to listen, clearness of speech, ability to document correctly, ability to act in a non-standard situation, ability to manage a group of people, striving for professional growth.
In total, 53 persons, namely, first year students of Law Faculty of National Aviation University (average age 17 years old) participated in the experiment. Herein, $60.4 \%$ of the sample were females. All participants were grouped according to one of the types of experimental conditions.

Individual matrices of the results of respondents' ranking of the suggested characteristics were reduced to separate matrices according to gender criterion. Average value of ranks, variance and standard deviations of the distribution of average values in MS Excel for Windows for each matrix were calculated.

Tables 1 and 2 show the results of rating distributions of characteristics of the image of "lawyer" in female students and male students of the first year.

Table 1. Results of rating distributions of characteristics of the image of "lawyer" in female students of the first year

\begin{tabular}{|c|c|}
\hline \multicolumn{2}{|l|}{ Female students } \\
\hline Ability to document correctly & 9.31 \\
\hline Objectivity of judgments & 9.22 \\
\hline Clearness of speech & 9.22 \\
\hline Timeliness of tasks performance & 9.06 \\
\hline Striving for professional growth & 9.03 \\
\hline Ability to listen & 9.0 \\
\hline Ability to act in a non-standard situation & 9.0 \\
\hline Confidence & 8.84 \\
\hline Independence of judgments & 8.81 \\
\hline Communicativeness & 8.78 \\
\hline Self-control & 8.78 \\
\hline Diligence & 8.75 \\
\hline Determinativeness & 8.72 \\
\hline Critical appraisal of facts & 8.69 \\
\hline Ability to manage time & 8.69 \\
\hline Analytical thinking & 8.66 \\
\hline Logic of judgments & 8.66 \\
\hline Accuracy in work & 8.63 \\
\hline Unbiased judgments & 8.59 \\
\hline Ability to model circumstances & 8.56 \\
\hline Tolerance & 8.25 \\
\hline Ability to select essential & 8.22 \\
\hline Ability to manage a group of people & 8.22 \\
\hline Democracy in communication & 8.13 \\
\hline Ability to set priorities & 8.03 \\
\hline Leadership qualities & 7.75 \\
\hline Ability to adapt in a team & 7.72 \\
\hline Self-assessment & 7.59 \\
\hline Adherence to principles in approaches & 7.28 \\
\hline
\end{tabular}


Table 2. Results of rating distributions of characteristics of the image of "lawyer" in male students of the first year

\begin{tabular}{|c|c|}
\hline \multicolumn{2}{|l|}{ Male students } \\
\hline Striving for professional growth & 9.14 \\
\hline Clearness of speech & 9.05 \\
\hline Confidence & 8.76 \\
\hline Self-control & 8.71 \\
\hline Ability to act in a non-standard situation & 8.71 \\
\hline Analytical thinking & 8.71 \\
\hline Logic of judgments & 8.67 \\
\hline Objectivity of judgment & 8.67 \\
\hline Ability to set priorities & 8.62 \\
\hline Critical appraisal of facts & 8.57 \\
\hline Timeliness of tasks performance & 8.57 \\
\hline Diligence & 8.52 \\
\hline Determinativeness & 8.48 \\
\hline Ability to model circumstances & 8.43 \\
\hline Ability to listen & 8.43 \\
\hline Ability to document correctly & 8.43 \\
\hline Ability to manage a group of people & 8.29 \\
\hline Ability to manage time & 8.24 \\
\hline Independence of judgment & 8.19 \\
\hline Ability to adapt in a team & 8.14 \\
\hline Accuracy in work & 7.95 \\
\hline Self-assessment & 7.9 \\
\hline Leadership qualities & 7.81 \\
\hline Communicativeness & 7.76 \\
\hline Democracy in communication & 7.67 \\
\hline Adherence to principles in approaches & 7.62 \\
\hline Ability to choose essential & 7.62 \\
\hline Tolerance & 7.38 \\
\hline Unbiased judgments & 7.24 \\
\hline
\end{tabular}

The variances of distribution of the average values practically coincide: 0.2341 - males, 0.2547 - females. However, there are differences in the distribution of ratings of the image of a lawyer in females and males: the reliability of differences in the characteristics of the compared samples (according to Wilcoxon-Mann-Whitney criterion) is $95 \%$.

It should be noted that a significant disadvantage of the rating method is that the survey may have low statistical power, that is, the ability to reveal differences between the groups. Moreover, low values of the indicators and low sample size reduce the power of the statistical criterion can lead to the fact that a statistical verification will show the absence of a distinction that actually exists (in statistics this is called a "error of the second kind"). Thus, we can come to improper conclusion that there is no difference, although in reality it is.

In the world literature on gender studies, the concept of value of the difference (a so-called "effect size", denoted by the symbol "d") is widely used. The value of the difference "d" is calculated for each study by evaluating an average of the one group from an average of the other group (in this case, an average for females is subtracted from an average for males), after which the obtained difference is divided by the internal group standard deviation [16], [17].

Jacob Cohen established that if " $\mathrm{d}$ " is 0.2 , then one can talk about the small difference, 0.5 is an average difference, and 0.8 is a large one [18].

In our research, the average values (and standard deviation) of the rating distributions for males and females respectively are $8.29(0.4924)$ and $8.56 \quad(0.5136)$. Accordingly, value of the difference " $\mathrm{d}$ " is 0.53 , that is, the average value of the difference in ranking of the results on a gender criterion.

Fig. 1 shows the difference between the average values of the results of the rank evaluation of the personal characteristics of the lawyer's image of males relatively females, who participated in the survey.

The diagram shows that females give totally higher marks in the ranking process to the personal characteristics of the image under the study.

To analyze the level of coincidence of rank positions in the distributions of characteristics in males $\left(\mathrm{N}_{\mathrm{i}}\right)$ and females $\left(\mathrm{N}_{\mathrm{j}}\right)$, we construct a graph of absolute differences of place in the rating of the certain characteristics $\left(\left|\mathrm{N}_{\mathrm{i}}-\mathrm{N}_{\mathrm{j}}\right|\right)$, giving the highest rank (1) to the value of the highest average in each rating distribution. Fig. 2 shows the results. 


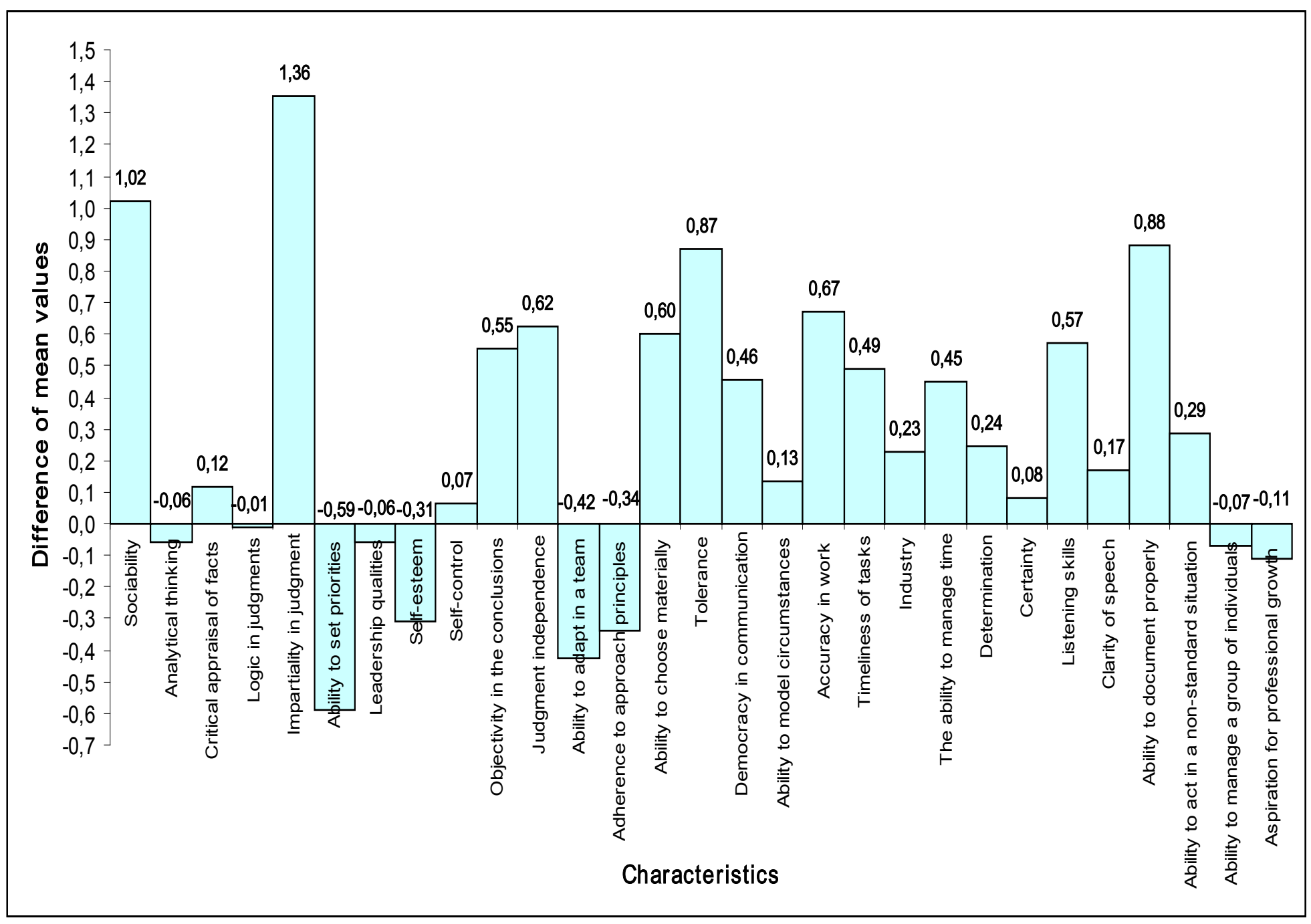

Figure 1. The difference between the average values of the results of the rank evaluation of the personal characteristics of the lawyer's image (females - males) 


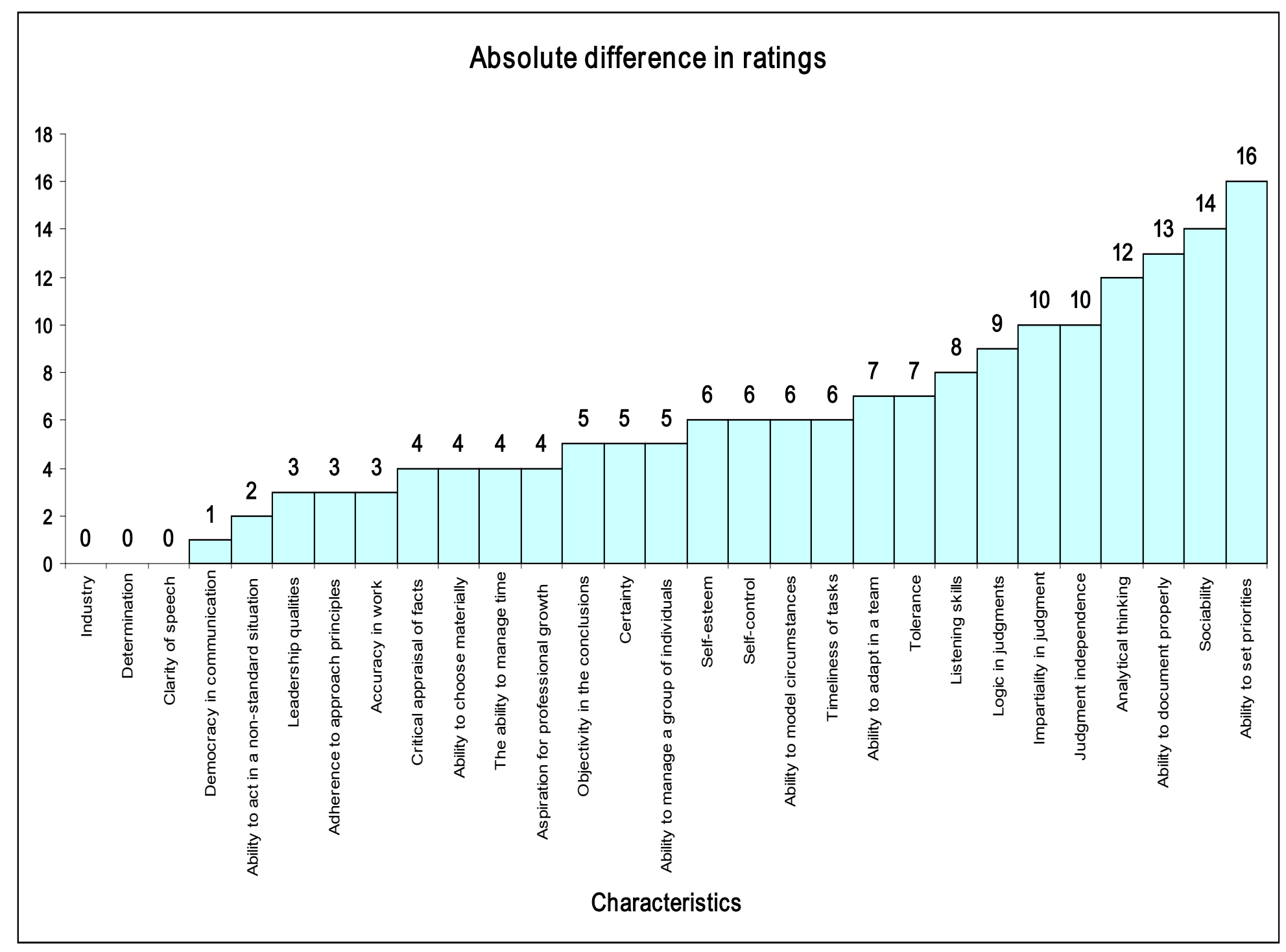

Figure 2. Absolute difference between rating scores of personal characteristics ranking of the lawyer's image in males and females 
Fig. 3 shows the difference in rating scores of personal characteristics ranking of the lawyer's image in males and females, where the sign (-) indicates the "lag" in the rank position of each characteristic in the ranking between males and females.

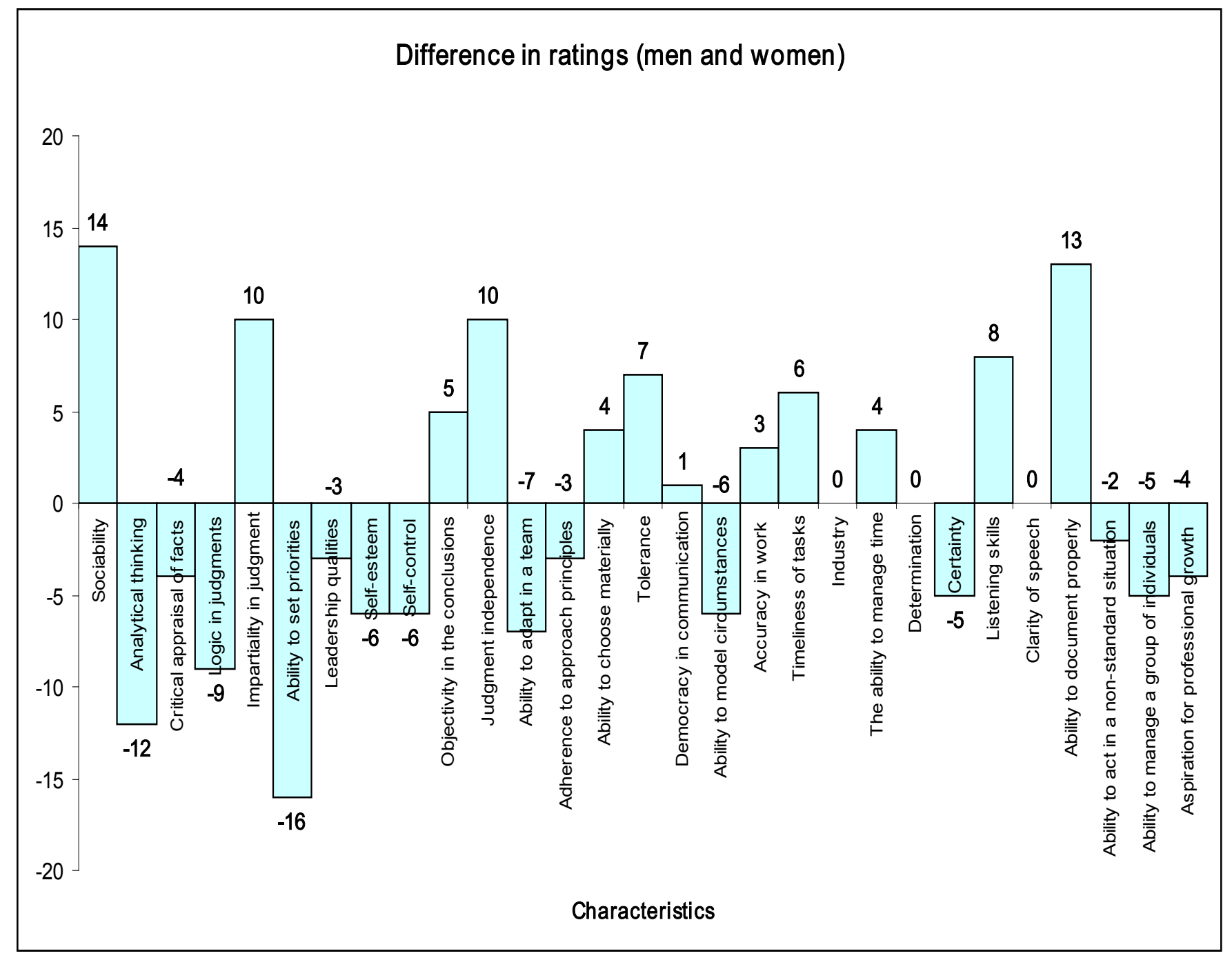

Figure 3. Difference between rating scores of personal characteristics ranking of the lawyer's image in males and females 
Factor analysis (FA) was used to reduce the dimension of the variable collections that describe a lawyer's image. The factors were distinguished by the principal components method; the factor scorings were used after rotation by the varimax method.

As one method of classification, factor analysis is based on correlations assessments (factor loadings) between baseline data and new indicators (factors). This allows determining the significance of factors within the factor model chosen by the researcher. In our case, using the method of rotation (varimax) hada possibility of a simple interpretation of factors based on difference of factor loadings, which allowed to classify the factors and to build a model of the phenomenon under the study.

This research, which is aimed at testing hypothesis of gender differences in students' conceptions, was conducted on a small sample size.

Table 3. Factorial description of the characteristics of the image of a lawyer in male students

\begin{tabular}{|l|l|}
\hline Strength of the individual & Factor 1 \\
\hline Ability to manage a group of people & 0.850869 \\
\hline Ability to model circumstances & 0.753622 \\
\hline Striving for professional growth & 0.675854 \\
\hline Ability to set priorities & 0.669162 \\
\hline Ability to act in a non-standard situation & 0.652052 \\
\hline Ability to select essential & 0.633829 \\
\hline Logic of judgments & 0.628313 \\
\hline Critical appraisal of facts & 0.625700 \\
\hline Fraction of total variance & $19.73 \%$ \\
\hline Social standardization & Factor 2 \\
\hline Ability to document correctly & 0.879623 \\
\hline Independence of judgments & 0.831132 \\
\hline Democracy in communication & 0.830885 \\
\hline Objectivity of judgments & 0.772277 \\
\hline Accuracy in work & 0.630439 \\
\hline Fraction of total variance & $18.41 \%$ \\
\hline Confidence & Factor 3 \\
\hline Confidence & 0.719816 \\
\hline Ability to listen & 0.668775 \\
\hline Timeliness of tasks performance & 0.608211 \\
\hline Fraction of total variance & $11.44 \%$ \\
\hline Self-control & Factor 4 \\
\hline Self-control & 0.798424 \\
\hline Self-assessment & 0.697891 \\
\hline Fraction of total variance & $11.35 \%$ \\
\hline
\end{tabular}

Due to the fact that in our case, as in many similar cases, increasing the sample size is not possible, small sample size is an important problem that has received considerable discussion in the scientific literature on factor analysis problems [19]. In the paper of Joost de Winter, Dimitra Dodou, \& Peter Wieringa [20] Exploratory Factor Analysis with Small Sample Sizes, Multivariate Behavioral Research it is showed that sample size $\mathrm{N}=50$ is an acceptable absolute minimum. The modelling was conducted to estimate the minimum required sample size for different loading levels, the number of factors and the number of variables, and to find out how far the sample can withstand small distortions such as correlations between factors, model error, secondary and unequal loads.

The authors concluded that stable loadings evaluations for sample sizes, even below 50, can be obtained under the conditions of high coincidence of a great number of observable variables and a small number of factors.

Based on the results of the research [21], the authors of which also recommend for small samples to be limited to a small number of expected factors, we have limited the number of factors to four. In general, the number of respondents (sample survey) meets all recommendations given in the paper [22].

Factorial description of the characteristics of the image of a lawyer in male students (Table 3).

Bartletts test of sphericity is satisfactory (322, $\mathrm{f}=21$, $\mathrm{p}<0.0001)$. The Kaiser-Meyer-Olkin (KMO) criterion of sample adequacy is 0.675 . There are four factors that explain $60.93 \%$ of the variance. As it is known [23], [24], if the cumulative (accumulated) percentage of the total variance reaches $60 \%$ or more, then it is possible to settle upon a given number of factors.

Factorial description of the characteristics of the image of a lawyer in female students (Table 4).

Table 4. Factorial description of the characteristics of the image of a lawyer in female students:

\begin{tabular}{|c|c|}
\hline Criticality & Factor 1 \\
\hline Critical appraisal of facts & 0.836605 \\
\hline Analytical thinking & 0.811062 \\
\hline Objectivity of judgment & 0.773234 \\
\hline Logic of judgments & 0.756998 \\
\hline Ability to model circumstances & 0.686058 \\
\hline Unbiased judgments & 0.669024 \\
\hline Communicativeness & 0.652944 \\
\hline Fraction of total variance & $20.32 \%$ \\
\hline Strength of the individual & Factor 2 \\
\hline Ability to select essential & 0.804333 \\
\hline Tolerance & 0.764685 \\
\hline Democracy in communication & 0.752203 \\
\hline Self-assessment & 0.690882 \\
\hline Independence of judgment & 0.689452 \\
\hline Clearness of speech & 0.678390 \\
\hline Ability to adapt in a team & 0.669043 \\
\hline Ability to set priorities & 0.664212 \\
\hline Adherence to principles in approaches & 0.654520 \\
\hline Fraction of total variance & $20.31 \%$ \\
\hline Social standardization & Factor 3 \\
\hline Timeliness of tasks performance & 0.797007 \\
\hline Determinativeness & 0.775664 \\
\hline Accuracy in work & 0.759265 \\
\hline Ability to manage time & 0.737343 \\
\hline Confidence & 0.703580 \\
\hline Ability to document correctly & 0.656888 \\
\hline Fraction of total variance & $18.63 \%$ \\
\hline Self-control & Factor 4 \\
\hline Self-control & 0.715985 \\
\hline Leadership qualities & 0.664499 \\
\hline Diligence & 0.647676 \\
\hline Fraction of total variance & $13.52 \%$ \\
\hline
\end{tabular}


Bartletts test of sphericity is satisfactory $(273, \mathrm{f}=32$, $\mathrm{p}<0.0001$ ). The Kaiser-Meyer-Olkin (KMO) criterion of sample adequacy is 0.751 . There are four factors that explain $72.51 \%$ of the variance.

As a result of data processing using the software "Statistica 10 for Windows" factor structures were distinguished and factor scales were found.

In each factor, dominant loadings had the characteristics listed below in order of decrease of factor loadings. The sets of characteristics that make up the distinguished factors allow them to be interpreted and formulated by an appropriate names given below. The names of the distinguished factors are conditionally formulated and can be discussed.

The table 5 shows the results of rating distributions of characteristics of the image of "lawyer" in female and male students of the first year of Law Faculty in accordance with the ranges of scores on the history of their EIE (External Independent Evaluation) certificate.

Table 5. Results of rating distributions of characteristics of the image of "lawyer" in female and male students

\begin{tabular}{|c|c|c|c|c|c|c|}
\hline \multirow{3}{*}{ Characteristics/Ranges of scores } & \multicolumn{6}{|c|}{ History test scores according to EIE (External Independent Evaluation) certificate } \\
\hline & \multicolumn{3}{|c|}{ Males } & \multicolumn{3}{|c|}{ Females } \\
\hline & $100-140$ & $150-168$ & $170-196$ & $100-140$ & $150-168$ & $170-196$ \\
\hline Communicativeness & 6.57 & 8.50 & 8.25 & 7.29 & 9.29 & 9.09 \\
\hline Analytical thinking & 8.86 & 8.75 & 8.50 & 7.14 & 8.71 & 9.55 \\
\hline Critical appraisal of facts & 7.57 & 9.38 & 8.50 & 7.00 & 9.21 & 9.09 \\
\hline Logic of judgments & 8.00 & 9.00 & 8.63 & 7.29 & 9.14 & 8.91 \\
\hline Unbiased judgments & 7.00 & 7.63 & 7.25 & 7.00 & 9.07 & 9.00 \\
\hline Ability to set priorities & 8.43 & 9.00 & 8.25 & 6.29 & 8.07 & 9.09 \\
\hline Leadership qualities & 7.71 & 8.75 & 7.13 & 6.57 & 8.29 & 7.82 \\
\hline Self-assessment & 8.86 & 8.00 & 7.38 & 7.43 & 7.50 & 7.82 \\
\hline Self-control & 9.29 & 8.75 & 8.50 & 8.71 & 9.00 & 8.55 \\
\hline Objectivity of judgment & 8.86 & 9.13 & 7.75 & 7.71 & 9.71 & 9.55 \\
\hline Independence of judgment & 8.57 & 9.25 & 7.13 & 7.71 & 8.93 & 9.36 \\
\hline Ability to adapt in a team & 8.14 & 8.88 & 7.50 & 6.14 & 8.21 & 8.09 \\
\hline Adherence to principles in approaches & 7.43 & 8.88 & 6.50 & 5.86 & 7.50 & 7.91 \\
\hline Ability to select essential & 8.14 & 8.00 & 6.88 & 6.14 & 8.64 & 9.00 \\
\hline Tolerance & 8.86 & 8.00 & 5.75 & 6.86 & 8.43 & 8.91 \\
\hline Democracy in communication & 8.86 & 7.63 & 6.50 & 6.71 & 8.50 & 8.55 \\
\hline Ability to model circumstances & 7.71 & 9.13 & 8.25 & 7.29 & 9.00 & 8.82 \\
\hline Accuracy in work & 8.57 & 9.38 & 6.25 & 7.43 & 9.07 & 8.82 \\
\hline Timeliness of tasks performance & 8.29 & 9.50 & 8.25 & 8.14 & 9.29 & 9.36 \\
\hline Diligence & 9.00 & 8.50 & 8.25 & 7.57 & 9.14 & 9.00 \\
\hline Ability to manage time & 8.14 & 8.88 & 8.13 & 7.29 & 9.07 & 9.09 \\
\hline Determinativeness & 7.43 & 9.50 & 8.38 & 7.14 & 9.07 & 9.27 \\
\hline Confidence & 8.14 & 9.63 & 8.63 & 7.43 & 9.07 & 9.45 \\
\hline Ability to listen & 8.43 & 9.13 & 7.75 & 7.57 & 9.43 & 9.36 \\
\hline Clearness of speech & 8.57 & 9.50 & 9.00 & 8.14 & 9.50 & 9.55 \\
\hline Ability to document correctly & 8.86 & 9.00 & 7.63 & 8.29 & 9.50 & 9.73 \\
\hline Ability to act in a non-standard situation & 8.14 & 9.25 & 8.63 & 7.71 & 9.50 & 9.18 \\
\hline Ability to manage a group of people & 7.29 & 9.00 & 8.63 & 7.43 & 8.50 & 8.36 \\
\hline Striving for professional growth & 9.14 & 9.50 & 8.75 & 8.43 & 9.07 & 9.36 \\
\hline
\end{tabular}


The results of the questionnaire were subjected to two-way variance analysis, which showed:

1. The power of influence of the factor "History test scores according to EIE" on the distribution of rating scores of characteristics of the image of "lawyer" in first year students of Law Faculty is: in females $62.53 \%(p<0.0001)$, in males $27.91 \%(p<0.0001)$.

2. The power of influence of the factor "content of the characteristic" is: in females $28.04 \%(\mathrm{p}<0.0001)$, in males $31.26 \%(p<0.0001)$.

3. For female students, the significance of differences in rating distributions in the range of 100-140 scores with the sample ranges of scores 160-168 and $170-196$ is $95 \%$, the characteristics of rating distributions of scores 160-168 and 170-196 coincide at the significance level of 0.05 .

4. Male students have $95 \%$ significance of differences in rating distributions among all ranges of scores.

\section{Conclusions}

The results of the experimental research confirm the significant influence of gender on the formation of primary stereotypes of professional activity in students in the field of law.

Two-factor analysis of variance proves that the stereotypes of a lawyer's professional image are directly related to personal stereotypes that motivate a choice of the future profession (rating distributions of characteristics of the profession image in the first year students by gender are correlated with the range of scores in a compulsory subject for admission to this speciality according to EIE (External Independent Evaluation) certificate.

In order to form in students, the stereotypical image of the future legal profession, which corresponds to the objective image of a professional of the respective field as closely as possible, it is considered appropriate to introduce appropriate didactic conditions in the educational process of higher education institutions.

Taking into account gender aspects, we suggest the following specific measures for improvement of the educational process of higher education institutions, namely: creation of equal opportunities for personal expression; expression of activity and initiative of students of both genders; use of active communication of processes on the basis of "gender alignment" (organization of discussions and joint discussions of educational problems and professional practical situations, role-playing games with involvement of students of both genders, use of collective methods and forms of organization of educational and cognitive activity of students in mixed groups); development of skills of gender reflection and partnership between students of different sexes; development of the ability of teachers to ensure gender equality in relation to the students audience.

The innovative nature of modern higher education is determined, in particular, by gender peculiarities in the organization of the educational process. This shall ensure the correspondence between a subjective image of a legal professional formed in the minds of students of different genders and professional realities.

\section{Acknowledgements}

The authors thank the Dean's Office of the Law Faculty National Aviation University for furtherance in conducting a sociological experiment.

\section{Appendix}

\section{QUESTIONNAIRE}

Course

Gender $\mathbf{M} / \mathbf{F}$ (enter the appropriate letter)

Rate on a scale of 1 to 10 the importance of the lawyer's personal characteristics (10 - maximum level)

\begin{tabular}{|l|l|l|}
\hline No. & Characteristics of student & $\begin{array}{l}\text { Mark } \\
(1 \ldots 10)\end{array}$ \\
\hline 1 & Communicativeness & \\
\hline 2 & Analytical thinking & \\
\hline 3 & Critical appraisal of facts & \\
\hline 4 & Logic of judgments & \\
\hline 5 & Unbiased judgments & \\
\hline 6 & Ability to set priorities & \\
\hline 7 & Leadership qualities & \\
\hline 8 & Self-assessment & \\
\hline 9 & Self-control & \\
\hline 10 & Objectivity of judgment & \\
\hline 11 & Independence of judgment & \\
\hline 12 & Ability to adapt in a team & \\
\hline 13 & Adherence to principles in approaches & \\
\hline 14 & Ability to select essential & \\
\hline 15 & Tolerance & \\
\hline 16 & Democracy in communication & \\
\hline 17 & Ability to model circumstances & \\
\hline 18 & Accuracy in work & \\
\hline 19 & Timeliness of tasks performance & \\
\hline 20 & Diligence & \\
\hline 21 & Ability to manage time & \\
\hline 22 & Determinativeness & \\
\hline 23 & Confidence & \\
\hline 24 & Ability to listen & \\
\hline 25 & Clearness of speech & \\
\hline 26 & Ability to document correctly & \\
\hline 27 & Ability to act in a non-standard situation & \\
\hline 28 & Ability to manage a group of people & \\
\hline 29 & Striving for professional growth & \\
\hline
\end{tabular}




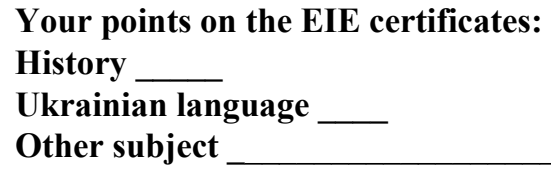

\section{REFERENCES}

[1] V. V. Ovsiannikova. The dynamics of the "image of your profession" depending on the degree of familiarization with it, Psychology Issue, Vol. 5, 133-137, 1981.

[2] Ada S. Chulef, Stephen J. Read, David A. Walsh. A hierarchical taxonomy of human goals, Notiv. And Emot, No. 3, 191-232, 2001.

[3] J. Elliott, N. Hufton. The roots of motivations: Classroom and cultural factors, Education Section Annual Conference of the British Psychological Society, Greenwich, Proc. Brit. Psychol. Soc., No. 1, 3, 2001.

[4] T. V. Kudriavtsev. Psychological analysis of the dynamics of professional personality self-determination, Psychology Issue, Vol. 2, 51-59, 1983.

[5] P. N. Shyhipiev. Social installation as a subject of socio-psychological research, Psychological problems of social regulation of behavior, n. No., 278-294, 1976.

[6] W. Lippman. Public opinion, Institute of the Public Opinion Foundation, Moscow, 2004.

[7] T. Ye. Vasileva. Stereotypes in public consciousness (socio-philosophical aspects), INION AN SSSR, Moscow, 1988.

[8] N. A. Rusina. The study of benchmarks and social stereotypes using semantic measurements, Psychology Issue, Vol. 5, 96-106, 1981.

[9] I. S. Con. Sociological Psychology: Selected Psychological Works, Voronezh, Moscow, 1999.

[10] B. Y. Bocheliuk. Legal psychology, TSUL, Kyiv, Ukraine, 2017.

[11] V. T. Nora. Fundamentals of General and Legal Psychology, In-Yure, Kyiv, 2014.

[12] A. M. Stoliarenko. Applied Legal Psychology, Yuniti-Diana, Moscow, 2001.

[13] Higher education standard in specialty 081 "Law" of the field of knowledge 08 "Law" for the first (bachelor) level of higher education, Online available from: https://mon.gov.u a/storage/app/media/vishcha-osvita/standarty

[14] L. Sijstma. Khroker. Introduction to classical and modern test theory with Eye toward learning potential testing. Learning potential assessment, Swets \& Zeitlinger B.V., Lisse, Netherland, 117-135, 1993.

[15] J. Grzegorek, A. P. Wierzbicki. Multiple Criteria Evaluation and Ranking of Social Penetration of Information Society Technologies, Journal of Telecommunications and Information Technology, No. 4, 3-13, 2011.

[16] J. S. Hyde. Gender and sex: So what has meta-analysis done for me? The Psychology Teacher Network Newsletter, No. 2, 2-6, 1992.

[17] J. S. Hyde, M. C. Linn. The psychology of gender: Advances through meta-analysis, Johns Hopkins University Press, Baltimore, 1986.

[18] J. Cohen. Statistical power analysis for the behavioral sciences, Academic Press, New York, 1969.

[19] S. S. Shaukat, T. A. Rao, M. A. Khan. Impact of sample size on principal component analysis ordination of an environmental data set: effects on eigenstructure, Ekológia (Bratislava), Vol. 35, No. 2, 173-190, 2016.

[20] J. C. F. De Winter, D. Dodou, P. A. Wieringa. Exploratory Factor Analysis with Small Sample Sizes, Multivariate Behavioral Research, Vol. 44, No.2, 147-181, 2009.

[21] Kristopher J. Preacher, Robert C. MacCallum. Exploratory Factor Analysis in Behavior Genetics Research: Factor Recovery with Small Sample Sizes, Behavior Genetics, Vol. 32, No. 2, 2002.

[22] Jung Sunho. Soonmook Lee Exploratory factor analysis for small samples, Behav Res, Vol. 43, 701-709, 2011. DOI 10.3758/s13428-011-0077-9.

[23] Lorenzo-Seva, U. How to report the percentage of explained common variance in exploratory factor analysis? Technical Report. Department of Psychology, Universitat Rovira i Virgili, Tarragona, 2013.

[24] J. L. Horn. A rationale and test for the number of factors in factor analysis, Psychometrika, Vol. 30, 179-185, 1965. 